\title{
THE PHYSIO-CHEMICAL AND MINERALOGICAL PROPERTIES OF MBADUKU CLAY AND ITS SUITABILITY AS AN INDUSTRIAL RAW MATERIAL
}

\author{
Amaakaven Victor $\mathbf{T}^{\mathbf{1}}$, Ali Edwin $\mathrm{A}^{\mathbf{2}}$, Idu Felix $\mathbf{U}^{\mathbf{3}}$ \\ ${ }^{\text {I}}$ Department of Ceramics and Glass technology, Akanu Ibiam federal polytechnic, Unwana \\ ${ }^{2}$ Department of Industrial Design, Ahmadu Bello University, Zaria ${ }^{\#}$ \\ ${ }^{3}$ Department of Ceramics and Glass technology, Akanu Ibiam federal polytechnic, Unwana
}

\begin{abstract}
Physio-chemical tests and mineralogical analysis were carried out on a clay sample from Vandeikya in Benue state with the aim of investigating to determine its suitability for industrial applications especially refractory and ceramic applications. The results obtained from x-ray fluorescence showed $\mathrm{Al}_{2} \mathrm{O}_{3} 34 \%$, $\mathrm{SiO}_{2} 54.4 \%, \mathrm{Fe}_{2} \mathrm{O}_{3} 8.9 \%$ and other minor oxides The plasticity test was also carried out and the clay has an Atterberg plasticity index of 8.15 which is slightly plastic. The result of the XRD, shows that the major minerals present are Hydrated alkali Alumino-Silicates of Sodium and potassium (Na,K)(Si $\left.i_{3} A l\right) O_{8}$, $\left.\mathrm{CaO} .2(\mathrm{Al}, \mathrm{Mg}) 2 \mathrm{Si}_{4} \mathrm{O}_{\mathrm{IO}}(\mathrm{OH})_{2} .4 \mathrm{H}_{2} \mathrm{O}\right)$ and kaolinite minerals $\left(\mathrm{Al}_{2} \mathrm{O}_{3} .2 \mathrm{SiO}_{2} .2 \mathrm{H}_{2} \mathrm{O}\right)$ and minerals like Crystobalite ( $\left.\mathrm{SiO}\right)_{2}$ and hydrated zinc Phosphate $\left(\mathrm{Zn}_{3}\left(\mathrm{PO}_{4}\right)_{2} \cdot 4 \mathrm{H}_{2} \mathrm{O}\right)$ being the minor or auxiliary minerals. This clay could find application in the manufacture of refractory materials, electrical insulators, glass ceramics, plastic products and in paint production if properly beneficiated.
\end{abstract}

Keywords: Vandeikya Clay, X-Ray fluorescence, X-Ray powder diffraction, untreated clay.

\section{INTRODUCTION}

According to the ASTM, designation 2478, (2006) clay is soil passing a no $200(75 \mu)$ U.S standard sieve that can be made to exhibit plasticity within a range of water contents and that exhibits considerable strength when air dry. Also according to Brain, (1971), Ahmed, (1986), and Nnuka et al, (1992), in Ahmed elal (2012), clays are aluminosilicate minerals (fine grained rocks) which when suitably crushed and pulverized becomes plastic when wet, leather hard when dried and on firing it is converted to a permanent rock. Sanni, (2005), States that clays are typically anhydrous complex compounds of Alumina $\left(\mathrm{Al}_{2} \mathrm{O}_{3}\right)$ and silica $\left(\mathrm{SiO}_{2}\right)$, which exist in various proportion and contain varied amount of impurities of iron, organic matters and residual minerals.

In the classification of clays for different applications, the chief determining factor is the proportions of silica and alumina in combination and their relative ratios. However, the presence of fluxing oxides such as $\mathrm{Na}_{2} \mathrm{O}$ and $\mathrm{K}_{2} \mathrm{O}$ in combination with the oxides of Iron tends to limit the clay to pottery applications and in some other cases low duty refractory applications. The inherent properties of ceramics and thus fired clay materials such as high strength, thermal insulation, chemical resistance and durability, wear resistance and the relative abundance of clay makes them most suitable for a wide range of applications ranging from house hold utensils to structural ceramics and in very rare cases functional ceramics.
Bain et al (1969), states that; in the evaluation of clay samples generally as commercial raw materials, impurities are of major concern. They may affect the commercial application or value of the clay deposit in several ways, which may include:

1. The presence of impurities may affect the physical or chemical properties of the clay in bulk.

2. With the knowledge of the nature of impurities present, its separation can be easily done to yield useful beneficiated clay with better properties and wider range applications.

\section{MATERIALS AND METHODS}

The clay samples were collected from a hand dug well which was dug for the purpose of water, in Mbaadigam village of Mbaduku district one of the many districts of Vandeikya local government area of Benue state, Nigeria. The entire area is composed relatively of abundant deposits of this clay. The clay sample was collected at random from the dugout soil at the site between depths of about 2 meters to 5 meters. The clay had a slightly visible stratified arrangement of about $4 \mathrm{~cm}$ to $9 \mathrm{~cm}$ apart. Once collected the lumps were then transported to Federal Polytechnic Unwana where it was then crushed and thoroughly mixed by quartering and coning method in order to achieve a representative homogeneous sample. A portion of the sample was then sent for chemical analysis at Centre for Energy Research and training (CERT) Zaria, using an XRF machine. About half of the crushed sample was then soaked in water for seven days, washed, and dried under ambient conditions on a cemented floor. Both washed and unwashed 
samples were tested for plasticity, loss on ignition, dry and firing and shrinkages .As earlier stated mineralogical analysis was carried out at the national steel raw material institute Kaduna, using X-Ray powder Diffractometer.

The equipment used included; jaw crusher, electric drying cabinet, manual and electronica digital weighing balances, an electric kiln and a stove respectively.

\subsection{Loss on Ignition (L.O.I)}

This generally entails the removal of water of crystallization and carbonaceous material through the application of heat.50g of the clay sample was weighed into a stainless steel crucible. The crucible was then heated in an electric kiln. The temperature gradually rose to $1000^{\circ} \mathrm{C}$ and maintained for one hour, the crucible was cooled inside a desiccator and weighed. After 15 minutes the crucible was reheated for another 20 minutes and reweighed to achieve a constant weight. The percentage loss on ignition was then evaluated using the expression below.

$$
\text { LOI }=\frac{\text { Ms }- \text { Mi }}{M s} \times 100
$$

Where: Ms = mass of sample before ignition in grams (g) $\mathrm{Mi}=$ mass of sample after ignition in grams $(\mathrm{g})$

\subsection{Shrinkages (Dry and Fired)}

The clay was soaked in water and left for two days, decanted and the clay poured out on a cemented floor and left to give a plastic consistency, it was then kneaded and rolled into a slab using a slab roller and cut into test tiles of $12 \mathrm{~cm} \times 5 \mathrm{~cm} \times 1 \mathrm{~cm}$ representing length, breadth and thickness respectively. The tiles were allowed to dry under ambient conditions for seven days and after which it was dried inside a drying cabinet at $110^{\circ} \mathrm{C}$ for 12 hours and allowed to cool after which their new lengths were then taken to determine its drying shrinkage. Subsequently the test tiles were heated gradually inside an electric kiln to a temperature of $1250^{\circ} \mathrm{C}$ and soaked at the temperature for 2 hours to determine its firing shrinkage. Their percentage drying and firing shrinkages were determined using these expressions:-

$$
\begin{aligned}
& \text { Ds } \%=\frac{\mathrm{Lw}-\mathrm{Ld}}{L w} \times 100 \\
& \text { Fs } \%=\frac{\mathrm{Ld}-\mathrm{Lf}}{L d} \times 100
\end{aligned}
$$

Where: Lw = wet length

Ld = dry length

Lf $=$ fired length

Ds $=$ Drying shrinkage

Fs $=$ fired shrinkage

\subsection{Plasticity}

The Atterberg plasticity index was carried out using the casagrande equipment in which the liquid and plastic limits of the clay was determined which was then used to compute the Plasticity Index. The liquid limit was determined by weighing the oven dried samples taken from the casagrande equipment and rolled into a thread of $3 \mathrm{~mm}$ on a glass kneading table after blowing limit of the clay was reached. The thread was not easy to roll as it crumbled a few times. The plastic limit was determined from the plot of liquid limit vs number of blows and hence plasticity index. These values were determined using the casagrande equipment at the Soil laboratory of Federal Polytechnic Unwana, in accordance with the ASTM Designation: D 4318 (2000)

$$
\text { LL-PL }=\text { PI }
$$

Where $\mathrm{LL}=$ Liquid limit

$\mathrm{PL}=$ Plastic limit

$\mathrm{PI}=$ Plasticity index

\subsection{Determination of Apparent Porosity.}

The clay was made into test bricks in cubical form with dimensions of $5 \times 5 \times 10 \mathrm{~cm}$ allowed to dry under ambient conditions for 7 days, after which they were oven dried at $110{ }^{\circ} \mathrm{C}$ until a constant weight $\left(\mathrm{W}_{1}\right)$ was obtained. The dried test pieces were then allowed to cool then suspended in a stainless steel pot containing distilled water and boiled for four hours in this position, while still in the water allowed to cool down to room temperature and its new weight $\left(\mathrm{W}_{2}\right)$ taken, the specimen was removed from water, and again reweighed in air to determine its water saturated weight $\left(\mathrm{W}_{3}\right)$. Apparent Porosity $\left(\mathrm{P}_{\mathrm{a}}\right)$ was determined by the expression in equation (5):

$$
\mathrm{P}_{\mathrm{a}}=\frac{W 3-W 1}{W 2-W 1} \times 100
$$

Where $\mathrm{w}_{1}=$ weight of dry sample

$\mathrm{W}_{2}=$ weight of fired test piece in water

$\mathrm{W}_{3}=$ weight of water saturated test piece

$\mathrm{P}_{\mathrm{a}=\text { apparent porosity }}$

\subsection{Chemical Analysis using XRF Technique.}

The sample was analysed using a Mini Pal 4 version (PW 4030) compact energy dispersive X-ray spectrometer. The samples to be analysed were weighed and ground to powder form using an agate mortar into a particle sizes within the range of $125 \mu \mathrm{m}$ and less. Pellets of $19 \mathrm{~mm}$ in diameter were prepared by carefully mixing small portions of an organic liquid as binder (PVC dissolved in toluene) and pressed with a hydraulic press to 10 tons. Each of the pellets was put in a plastic holder because there would be no interaction with the primary X-rays emerging from the X-ray tube window and the plastic holder. The holder and specimen were then loaded into the specimen chamber of the spectrometer and the instrument operated at $30 \mathrm{kV}$ and $1 \mathrm{~mA}$ for $10 \mathrm{mins}$. The primary X-rays would excite secondary emissions characteristic of the elements being analysed and the spectrum analysed to determine the concentration of the elements in the sample. 


\subsection{Mineralogical Analysis}

The untreated clay sample was analysed using an XRD to determine its mineralogical constituents. The raw clay was crushed and pulverized and prepared based on the principle of sedimentation. The sample was placed on the specimen holder of a Diffractometer. The type PX1800 Diffractometer is however controlled by a computer. It has an automatic divergence and scatter slit of 1.00 degrees each and a receiving slit of $0.300 \mathrm{~mm}$ and a $\mathrm{Cu}$ anode emitting primary X-Rays of wavelengths of $\lambda_{1}=1.54056 \AA$ and $\lambda_{2}=1.54439$
$\AA$. The machine operated at $40 \mathrm{kV}$ and a current of $30 \mathrm{~mA}$. The automatic scanning routines allowed for values of $2 \theta$ from $2^{0}$ to $65^{\circ}$ using a step size of $0.02^{0}$ and time per step of $0.24 \mathrm{~s}$ with a peak search intensity threshold of 30 per mil.

\section{RESULTS AND DISCUSSION}

The results of the experiments and analysis carried out which include physical, chemical and mineralogical are presented in tables 1-3 and fig 1and 2, and are discussed as follows:

Table 1 Some Physical Properties of Vandeikya Clay compared to other local clays as adapted from Ahmed and Abdullahi (2012)

\begin{tabular}{|l|l|l|l|}
\hline Clay & Colour & Physical form & Lump sizes as mined \\
\hline Vandeikya* & $\begin{array}{l}\text { White with little } \\
\text { brown patches }\end{array}$ & $\begin{array}{l}\text { Soft, smooth, powdery } \\
\text { lumps }\end{array}$ & $\mathbf{7 - 2 5 c m}$ \\
\hline Onibode & Light Grey & $\begin{array}{l}\text { Hard lumps, smooth } \\
\text { touch }\end{array}$ & $30-40 \mathrm{~cm}$ \\
\hline Kankara & White & $\begin{array}{l}\text { Soft, smooth, powdery } \\
\text { lumps }\end{array}$ & Less than 5cm \\
\hline Manjohota & Cream & $\begin{array}{l}\text { Moderately hard, } \\
\text { smooth touch }\end{array}$ & $10-20 \mathrm{~cm}$ \\
\hline Ahoko & Light grey & $\begin{array}{l}\text { Moderately hard, } \\
\text { smooth touch }\end{array}$ & $5-20 \mathrm{~cm}$ \\
\hline Waram & Ash grey lumps, & $20-40 \mathrm{~cm}$ \\
\hline Nafuta & $\begin{array}{l}\text { Very hard leam with brown } \\
\text { smooth }\end{array}$ & $\begin{array}{l}\text { Hard lumps coarse } \\
\text { texture. }\end{array}$ & $5-15 \mathrm{~cm}$ \\
\hline
\end{tabular}

Table 2 Wet, Drying and firing behavior of Vandeikya clay Talabi,(2012)

\begin{tabular}{|l|l|l|l|l|l|}
\hline parameters & Wet & Dry $\left(\mathbf{1 1 0}^{\mathbf{0}}\right)$ & $\begin{array}{l}\text { Apparent Porosity } \\
\mathbf{\%}\end{array}$ & Firing $\left(\mathbf{1 2 5 0}^{\mathbf{0}} \mathbf{C}\right)$ & Shrinkages \\
\hline colour & Pale purple & cream & $\mathbf{2 4 . 6 5}$ & White & Dry $5.5 \%$ \\
\cline { 5 - 6 } $\begin{array}{l}\text { Crack } \\
\text { formation }\end{array}$ & present & Slight & & Less cracks & Fired $3.92 \%$ \\
\hline
\end{tabular}

Table 3 Chemical Composition of Vandeikya Clay compared with previous research

\begin{tabular}{|l|l|l|l|l|l|}
\hline Oxides & $\begin{array}{l}\text { Vandeikya } \\
\text { clay }\end{array}$ & Ideal kaoline & Ikere clay & Ibadan clay & Jos Clay \\
\hline $\mathrm{Al}_{2} \mathrm{O}_{3}$ & $\mathbf{3 4 . 0 \%}$ & $39.49 \%$ & $34.41 \%$ & $37.54 \%$ & $37.71 \%$ \\
\hline $\mathrm{SiO}_{2}$ & $\mathbf{5 4 . 4 \%}$ & $46.0 \%$ & $49.85 \%$ & $44.98 \%$ & $46.60 \%$ \\
\hline $\mathrm{TiO}_{2}$ & $\mathbf{0 . 6 0 3 \%}$ & - & & & \\
\hline $\mathrm{Fe}_{2} \mathrm{O}_{3}$ & $\mathbf{8 . 9 2 8 \%}$ & - & & & \\
\hline
\end{tabular}

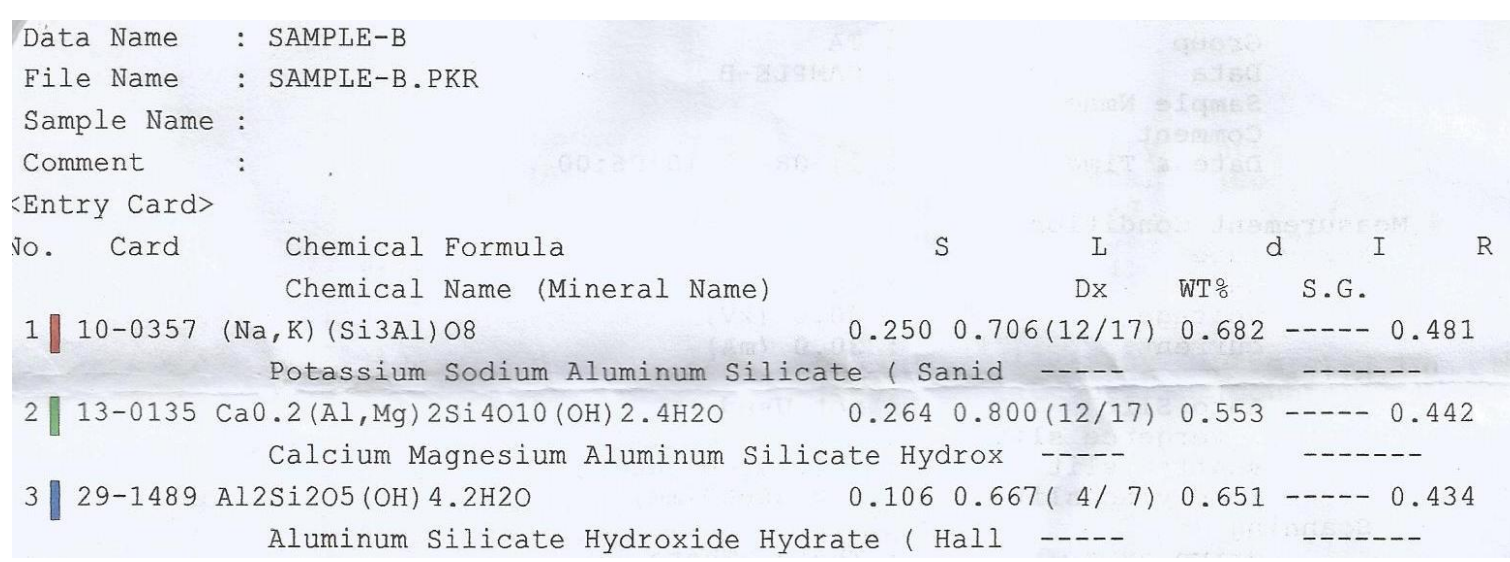

Plate 1 showing result of the mineralogical analysis in order of relative abundance of the minerals present. 


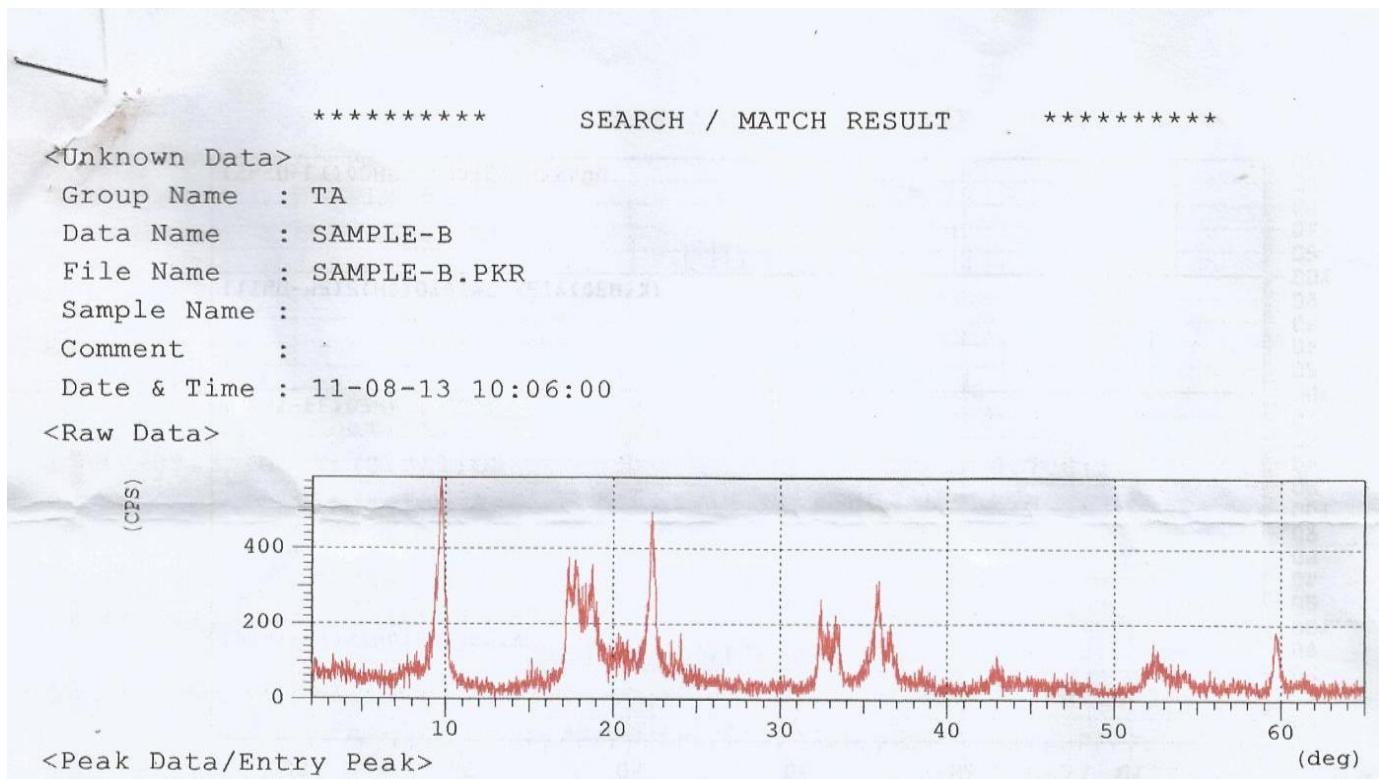

Fig. 1 diffractogram of Vandeikya bulk clay

\subsection{Loss on Ignition and Apparent Porosity}

The loss on ignition was determined after heating to a temperature of $1000^{\circ} \mathrm{C}$ to be $14.64 \%$ this showed that Vandeikya contains organic matter and water of crystallization as revealed by the XRD. The apparent porosity was also determined using the procedure above with formula (4) to be $24.65 \%$.

\subsection{Atterberg Plasticity Index}

As stated above, the result show a low plasticity index of 8.15 , a liquid limit of $42 \%$ and plastic limit of $33.85 \%$

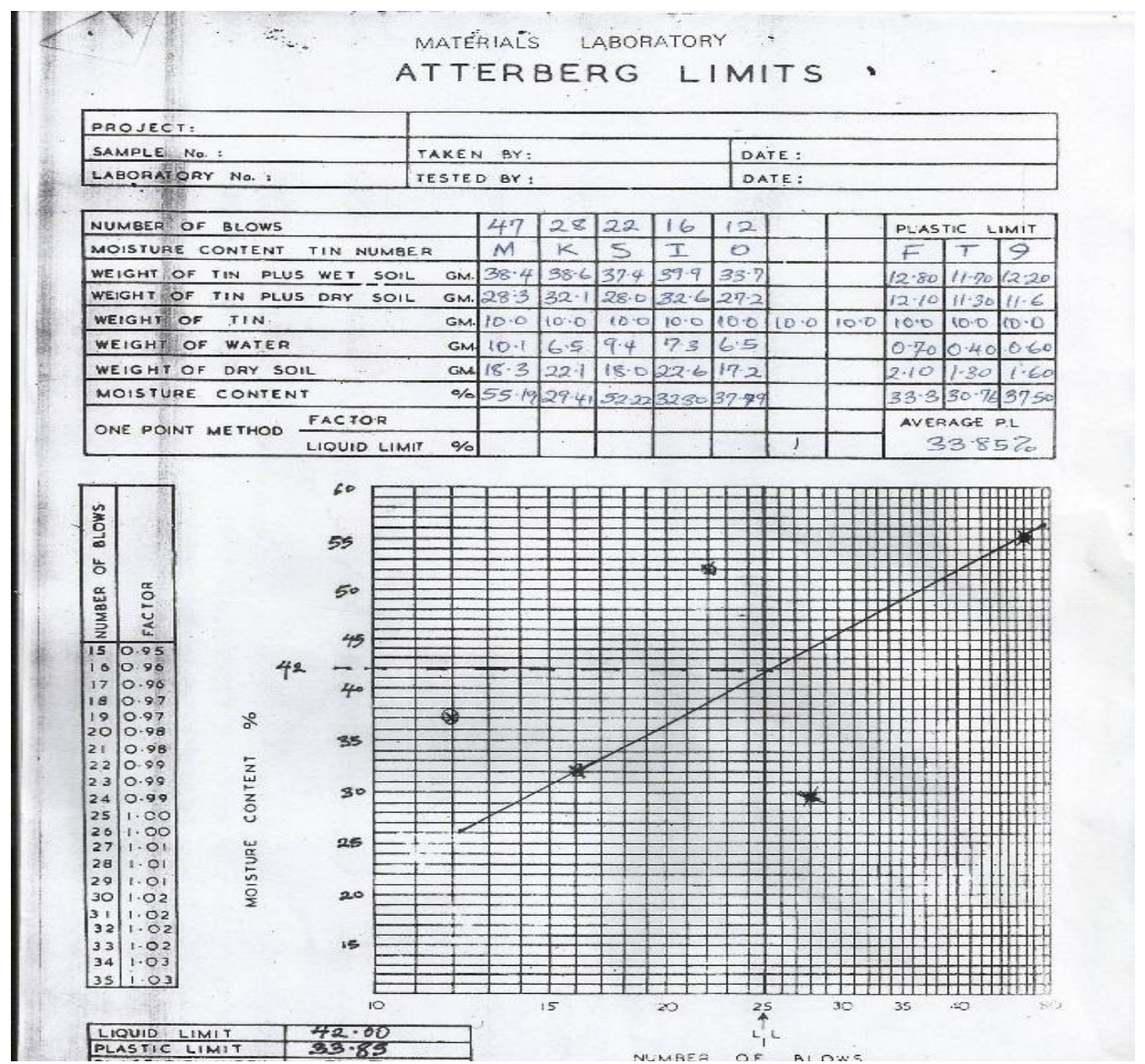

Fig. 2 showing the plot of moisture content against liquid limit for plasticity index. 


\subsection{Dried and Fired Shrinkages}

The results showed that the clay has a varied coloration in its raw, wet, dry and fired states. The raw clay showed a white Colour with small brown spots, while soaked its Colour changed to pale pink and on firing at $110^{\circ} \mathrm{C}$ it became cream and at $1250^{\circ} \mathrm{C}$ became white. The raw clay is moderately soft and is smooth to touch easily is disintegrates into loose powder. The dry shrinkage value was $5.5 \%$, with the fired shrinkage having a value of $3.92 \%$. However, according to Ahmed et al (2012), drying shrinkage is of little significance since the value changes with moisture content. The temperature of $1250^{\circ} \mathrm{C}$ was however not enough to properly fuse the test tile as it had low strengths compared to other clays fired at that temperature.

\subsection{Mineralogical Compositions}

The diffractogram in fig. 1 of the clay analysed shows three distinct peaks and two not very high peaks with the first highest peak at $9.8284^{0} 2 \theta(\mathrm{d}=8.99212 \AA)$, the second at $22.3923^{0} 2 \theta(\mathrm{d}=3.96717 \AA)$ and the third at $17.8285^{\circ} 2 \theta(\mathrm{d}=$ $4.97109 \AA)$. This indicates a dominance of Potassium Sodium Aluminum Silicate $(\mathrm{Na}, \mathrm{K})\left(\mathrm{Si}_{3} \mathrm{Al}\right) \mathrm{O}_{8}$, Calcium Magnesium Aluminum Silicate (CaO.2(Al, $\left.\mathrm{Mg}) 2 \mathrm{Si}_{4} \mathrm{O}_{10}(\mathrm{OH})_{2} \cdot 4 \mathrm{H}_{2} \mathrm{O}\right)$ and Aluminum Silicate Hydroxide $\left(\mathrm{Al}_{2} \mathrm{Si}_{2}(\mathrm{OH})_{4} \cdot 2 \mathrm{H}_{2} \mathrm{O}\right)$. There were also low peaks of $\mathrm{SiO}_{2}$ (crystabolite), Zinc Phosphate (Hopeite), Aluminum Silicate Hydroxide (Dickite), Titanium Oxide (Rutile) and Aluminum Silicate Hydroxide (Kaolinite) Minerals.

\section{CONCLUSIONS}

Physio-chemical composition and mineralogical characteristics of this clay were tested with a view to determining its suitability as an industrial raw material. From the study, it is obtained that Vandeikya clay deposit is predominantly kaolinite based on the ratio of Silica to Aluminum of $54 \%$ : $34 \%$ with mixtures of alkali oxides in small quantities but with a high $\mathrm{Fe}_{2} \mathrm{O}_{3}$ value of $8.928 \%$, and a mineral composition of. Accordingly, the grains size of a clay and their packing factor and composition greatly controls ceramic strength, shrinkage, and density. It could be used in refractory bricks if beneficiated properly by removing iron content through soaking water or washing to make it suitable for a wider range of applications. However, Vandeikya clay could also be useful for ceramic and the paint industries in Nigeria,

\section{REFERENCES}

[1] Ahmed, A.S and Abdullahi, Y (2012). Physiochemical and mineralogical studies of Ahoko clay for Industrial applications. Journal of Nigerian materials Society. 3(1) Pp 24-29

[2] Aref, A. A. and Lei, X. R. (2009). Characterization and Evaluation of Alga Kaolin Deposits of Yemen for Industrial Application. American J. of Engineering and Applied Sciences. Vol. 2 No 2, pp 292-296.

[3] ASTM Designation 2487 (2006) Standard Practice for Classification of Soils for Engineering Purposes (Unified Soil Classification System)
[4] ASTM Designation: D 4318 (2000). Standard Test Methods for Liquid Limit, Plastic Limit, and Plasticity Index of Soils.

[5] Bain J. A.and Morgan D. J. (1969). The Role of Thermal Analysis in the Evaluation of impure clay deposits as mineral raw materials. Institute of Geological Sciences, London. Clay Minerals 8, Pp 171-192

[6] Murray H. H. (2007) Applied Clay Mineralogy: Occurrences, Processing and Application of Kaolins, Bentonites, Palygorskite- Sepolite, and Common Clays. Elsevier, Amsterdam

[7] Rahaman, M. N. Ceramics processing and Sintering (2nd Ed) (2007). http://www. CeramicProcessingAndSintering.RAHAMAN.Segun daEdici\%F3n.pdf

[8] Talabi, A.O, Ademilua O. L and Akinola O. O. (2012) Compositional features and industrial applications of Ikere kaolinite, Southwest Nigeria. Research Journal in Engineering and Applied Sciences 1(5) 327-333

[9] Sanni, A. G (2005): Production of Proto-Type Fireclay Refractories Bricks from Oza-Nagogo Clay. Research Document of National Metallurgical Development Centre (NMDC), Jos. Nigeria. Presented at an In-House - Seminar on the 8th September, 2005. 